\title{
Notas sobre a experiência de trabalho fabril contemporânea: um estudo de caso em uma metalúrgica no $\mathrm{ABC}$ paulista
}

\author{
Bernardo Parodi Svartman ${ }^{1}$ \\ Pontifícia Universidade Católica de São Paulo
}

\begin{abstract}
Este artigo visa discutir os impactos das atuais formas de organização do trabalho fabril sobre a experiência psicossocial do trabalho e sobre a saúde dos trabalhadores. Apoiaremos essa discussão em um estudo de caso realizado numa metalúrgica da região do $\mathrm{ABC}$ paulista. A metodologia utilizada foi a de uma pesquisa de campo em regime de observação participante. Por meio da redação de um diário de campo, registramos episódios e observações que pareciam melhor descrever as experiências do trabalho. Buscamos comparar os dados obtidos na pesquisa de campo com a bibliografia relacionada à descrição das atuais transformações da gestão do trabalho fabril. Essa discussão abriga uma polêmica: as novas formas de gestão do trabalho fabril permitem uma maior participação do trabalhador na realização do trabalho ou ainda existem formas rígidas de controle apoiadas na separação entre concepção e execução do trabalho? Os dados empíricos permitem constatar que a organização do trabalho ainda se apoia sobre um sistema técnico que alia a separação entre concepção e execução a um sistema de vigilância e controle das atividades dos trabalhadores. Além desses fatores, aliam-se ao sofrimento no trabalho as novas formas de precarização e de flexibilização do regime de contratação de mão-de-obra.
\end{abstract}

Palavras-chave: Experiência de trabalho, Fábrica, Sofrimento, Flexibilidade, Estudo de caso.

Impacts of flexible conditions on factory work experience: a study case in a metallurgy of ABC's region of São Paulo State

The focus of this article is to discuss the impact of nowadays' transformations of the factory work context on the work experience and on the suffering caused by its organization. We are going to present a study case ran in a metallurgy of ABC's region of São Paulo State. The methodology used was field research in participant observation regime. Through the use of field diary writings, episodes and observations that seemed to better describe the experience of work were collected. We aimed to compare the collected data in the research field with the literature related to the description of nowadays transformations in the factory work management. This discussion puts an end to a polemic: Do the new forms of factory work management allow a bigger participation of the worker in the work itself or there are still rigid forms of control and separation between conception and execution of the work? The empirical data leads us to conclude that the work organization still relies on a technical system that adds separation between conception and execution to a vigilant and controlling system of the factory activities. Besides theses factors, the new forms of precarization and flexibilization of the labor contract regime are added to the suffering in work.

Keywords: Work experience, Factory, Suffering, Flexibility, Case study.

\section{Introdução}

$\mathrm{O}$ sociólogos dedicados à investigação do trabalho descrevem importantes mudanças ocorridas na organização da produção industrial a partir de meados da década de setenta. Segundo alguns autores de orientação marxista, como Ricardo Antunes (2002) e Jacob Gorender (1999), essas mudanças refletem uma ofensiva das empresas no sentido de recuperar os níveis de acumulação que estavam em queda a partir dessa época. As mudanças tiveram como objetivo enfrentar uma crise gerada pela tendência geral de queda da taxa de lucro e pelo esgotamento do padrão de acumulação fordista-taylorista (Antunes, 2002). As dificuldades no processo de acumulação do capital e a queda na taxa de lucro motivaram o acirramento da

1 Psicólogo e mestre em psicologia social. Doutorando no Departamento de Psicologia Social e do Trabalho do Instituto de Psicologia da Universidade de São Paulo. 
concorrência entre as empresas e a introdução de inovações tecnológicas e organizacionais na produção (Gorender, 1999). Do ponto de vista do capital, tornou-se necessária uma resposta à crise que envolvesse a reestruturação da produção e do trabalho visando repor os patamares de acumulação do período anterior, especialmente o padrão estabelecido nos anos pós 1945 (Antunes, 2002).

Nesse atual contexto, alguns fenômenos são igualmente importantes para caracterizar as transformações do trabalho fabril: a formação das empresas-rede, o processo de terceirização e as novas formas de organizar o trabalho no chão-de-fábrica. Essas novas formas de gestão do trabalho procuram tornar a produção flexível, ou seja, capaz de adaptar-se rapidamente a diferentes exigências e contingências do mercado. A introdução do trabalho por equipe, o enxugamento dos estoques e o controle de qualidade com o objetivo da extinção total de defeitos são alguns desses novos elementos organizacionais (Gorender, 1999).

As empresas reduziram significativamente as estruturas produtivas verticalizadas, estabelecendo ao mesmo tempo vínculos mais estreitos com seus fornecedores. Forma-se o modelo da "empresa-rede", composta de uma empresa matriz terminal (onde geralmente estão os trabalhos mais qualificados e que envolvem maior utilização de inovações tecnológicas) ligada a empresas fornecedoras associadas em graus variados, frequentemente em regime de subcontratação temporária (Gorender, 1999). Esse fator ajuda a compreender a atual diferenciação no interior da classe trabalhadora quanto a qualificação e ganhos salariais. Como afirma Blanch (2003), nesse sistema de empresas-rede, geralmente as matrizes concentram os trabalhadores mais qualificados, com melhores condições de trabalho e ganhos salariais, enquanto as mais periféricas encerram formas de trabalho arcaicas, com piores condições de trabalho e salários muito inferiores aos praticados nas empresas matrizes (Blanch, 2003).

O novo contexto produtivo é complexo devido justamente à soma de todos esses elementos. Ainda assim, pode-se perceber que elementos do modelo japonês de organização do trabalho fabril estão amplamente difundidos e criam um contexto comum no qual se inserem os trabalhadores operários. Como podemos observar a partir da revisão bibliográfica sobre o tema, presente na tese de Márcia Hespanhol Bernardo (2006), a ideia de flexibilidade relacionada à produção adquire um caráter polissêmico, mas o modelo de produção toyotista é o principal referencial desse processo (Bernardo, 2006).

Os princípios organizacionais formulados por Taiichi Ohno na fábrica da Toyota difundiram-se para todo o ocidente, sendo que alguns de seus princípios passam a caracterizar a maior parte dos ambientes de trabalho fabris (Ferro, 1990). De acordo com Ferro, os elementos da gestão do trabalho que se difundiram a partir da fábrica Toyota são os seguintes: just in time, muda e kaisen. O just in time é considerado o coração desse sistema de produção. Significa planejar uma produção em fluxo sem estoques. As partes certas, necessárias em cada etapa, devem chegar no momento exato e somente na quantidade necessária (Ferro, 1990). A produção é pensada ao contrário, do fim para o começo. O operador vai até o processo anterior pegar apenas o material e peças necessários (Ferro, 1990). As vantagens apontadas são as seguintes: possibilidade de observação imediata dos problemas durante a produção e a possibilidade de reduzir estoques e de adaptar rapidamente os níveis de produção às exigências do mercado. O segundo elemento do sistema, muda, significa eliminar totalmente desperdícios de material, pessoal, movimentos, peças defeituosas, transportes desnecessários, esperas, etc. (Ferro, 1990). O terceiro elemento, kaisen, significa o melhoramento contínuo da produtividade e da qualidade. É dentro deste elemento que se inserem os CCQ (Círculos de Controle de Qualidade), nos quais os operários são incentivados a discutir sugestões para o desenvolvimento de melhorias na qualidade da produção.

Um outro aspecto do novo contexto produtivo fabril, muito relacionado ao toyotismo, é apresentado pelo sociólogo Jean Pierre Durand. Segundo o autor, de certa forma, todas as fábricas, tanto pequenas como grandes, passam a ser afetadas pelo modelo de fluxo tensionado de 
produção (Durand, 2003). Para ele, o atual contexto produtivo é composto de três elementos: a integração reticular (a formação de redes de produção que afetam tanto o setor fabril, como o de serviços), a generalização do fluxo tensionado (com todas as consequências sobre a organização do trabalho) e a gestão por competências (novo meio de mobilização da mão-deobra). Sobre o modelo de fluxo tensionado, afirma Durand (2003):

O fluxo tensionado nasceu com a pilotagem pelo fim, isto é, a ideia de que só se deveria fabricar aquilo que o mercado já tenha pedido. Tal conceito generalizado a toda a cadeia de produção significa que cada posto de trabalho é cliente daquele logo acima, o qual, na incerteza do que lhe será demandado, não constitui mais estoques como no fluxo fordiano. Basta estar em condições de entregar à jusante, no momento certo (just-in-time) e segundo a quantidade demandada, os produtos ou serviços necessários (p. 143).

Ainda segundo esse autor, o modelo da competência também afetou de forma marcante o espaço fabril. Nesse modelo, o sistema de remuneração caminhou na direção de uma individualização das negociações salariais (Durand, 2003). As direções tendem a remunerar mais e mais o grau de mobilização dos empregados tomados individualmente, o grau de adesão às exigências da empresa.

O discurso na área da gestão empresarial relaciona essas inovações organizacionais e tecnológicas à superação da rigidez taylorista-fordista. Essa superação estaria apoiada em quatro pilares: a competência, a participação, o trabalho em equipe e a autonomia no local de trabalho (Bernardo, 2006). Segundo Taiichi Ohno (1997), mentor das transformações na fábrica Toyota, seu sistema permite desenvolver “(...) a habilidade humana até sua mais plena capacidade, a fim de melhor realçar a criatividade e a operosidade, para utilizar bem instalações e máquinas, e eliminar todo o desperdício" (p. 30). Temos um exemplo da ideia de uma ruptura entre os modelos no artigo de Ferro (1990), no qual o autor apresenta as intenções de Ohno na formulação do sistema toyota de produção:

Além disso [Ohno] queria recuperar a tradição do trabalho artesanal de englobar cabeça e mãos no processo produtivo, que havia sido destruída pelo sistema taylorista-fordista. Ohno conseguiu tudo isso (p. 58).

Em outro momento afirma:

Apesar de todas as inovações e revoluções tecnológicas trazidas pelo STP (sistema toyota de produção), sem dúvida, sua força fundamental encontra-se na qualidade e motivação do pessoal. O aproveitamento da potencialidade humana em todos os seus níveis é um dos grandes méritos do sistema. A ênfase é no trabalho em grupo e na cooperação (p. 62).

Um ponto de vista contrário abre-se, por exemplo, a partir da leitura das publicações do Departamento Intersindical de Estatística e Estudos Socioeconômicos (DIEESE) sobre a reestruturação produtiva. A polivalência e os círculos de controle de qualidade são questionados quanto ao seu potencial de elevar a participação e a qualificação dos trabalhadores. Segundo os boletins do DIEESE, refletindo o entendimento do sindicato dos metalúrgicos sobre o assunto, nos CCQs os trabalhadores são ouvidos apenas se oferecem sugestões para diminuir custos produtivos. Os trabalhadores que reivindicam melhores condições de trabalho são excluídos dos círculos e a polivalência significa alimentar um maior número de máquinas automáticas, máquinas que muitas vezes dispensam o conhecimento do operador sobre seu funcionamento (DIEESE, 1994). No livro Riqueza e miséria do trabalho no Brasil, organizado por Ricardo Antunes, encontra-se uma coletânea de pesquisas que reforçam esse entendimento sobre as características da reestruturação produtiva em vários setores econômicos. No setor metalúrgico, especificamente nas montadoras do ABC paulista, as 
conclusões das pesquisas apontam para um processo de cooptação dos trabalhadores em benefício da acumulação e do aumento da produtividade (Antunes, 2006).

Observar esse quadro sociológico das transformações do trabalho fabril e os textos sobre as novas formas de gestão nos leva a indagar em que medida esse processo afetou a experiência do trabalho operário. As considerações sobre o novo contexto fabril nos fazem levantar as seguintes perguntas: 1) os trabalhadores sentem efetivamente que há maior espaço de participação e desenvolvimento de habilidades pessoais no ambiente de trabalho? 2) qual o impacto da forma flexível de produção sobre a experiência de estabilidade e segurança no emprego? 3) o contexto de acirramento da concorrência entre as empresas, a introdução de novas tecnologias e formas de organização visando melhorar a lucratividade, tudo isso seria compatível com efetivas melhorias das condições de trabalho ou representam antes novas formas de "racionalização" do trabalho?

Vamos procurar responder essas perguntas analisando o material recolhido durante uma pesquisa de campo em regime de observação participante em uma metalúrgica da região do ABC paulista. Trata-se de um estudo de caso em uma metalúrgica prestadora de serviços para outras indústrias da região, localizada na periferia da organização reticular da produção industrial. As características do fluxo tensionado da produção tais como apresentados por Durand (determinadas pela relação da empresa com as fábricas clientes), assim como o essencial do modelo de avaliação por competências e a terceirização (tanto na relação com outras fábricas, como na relação com o grupo de trabalhadores no interior da fábrica), mostraram-se como os principais fatores do novo contexto produtivo que influenciam a fábrica pesquisada. Apresentaremos primeiramente o sistema técnico da fábrica para analisar as condições de participação dos trabalhadores na gestão e na realização das atividades. Veremos também com maiores detalhes em que medida algumas características do modelo japonês afetam essa organização do trabalho, como mesclam-se com as características tayloristas e, finalmente, como afetam a experiência de trabalho.

\section{O método da pesquisa: a observação participante}

Os dados utilizados neste artigo foram recolhidos em regime de observação participante, tendo o pesquisador trabalhado um dia por semana como ajudante geral em uma metalúrgica da região do $\mathrm{ABC}$ paulista, durante dois anos. Na pesquisa realizada durante o mestrado, buscamos apresentar o testemunho e a discussão de uma experiência pessoalmente assumida no trabalho fabril. A partir de um diário de campo e também do contato e conversas com os trabalhadores, procuramos identificar os episódios e as palavras que pareceram melhor descrever a experiência de trabalho na fábrica. Utilizaremos parte desse material de campo para discutir as condições de participação e a experiência de instabilidade e imprevisibilidade no trabalho.

Apoiando-nos nas lições de José Moura Gonçalves Filho sobre a observação participante, procuramos não realizar uma descrição particularista (demais pessoal) e tampouco uma descrição geral e abstrata da experiência de trabalho na fábrica (Gonçalves Filho, 2003). Buscamos realizar uma narrativa e uma discussão que tivessem provado algum encontro e desencontro entre a experiência do pesquisador e a de trabalhadores veteranos: um ponto de vista que revele comunicação entre elas e que, desde então, fosse informada por um diálogo com os trabalhadores sobre os fenômenos investigados (Gonçalves Filho, 2003).

Esta pesquisa de campo foi realizada como um esforço etnográfico de notações, discussão e levantamento de questões. Buscou-se compreender algo da experiência de trabalho fabril através da convivência e do diálogo com trabalhadores no próprio chão-de-fábrica. 
Aprendemos com Clifford Geertz que nisto consiste um texto etnográfico como empreendimento cientifico: tentar apreender estruturas de significação em campo, realizar uma descrição densa dos fenômenos, formular a condição para a qual nos deslocamos e na qual imaginamos, sempre excessivamente, estarmos então situados (Geertz, 1989). Buscar a convivência e o diálogo de perto, situar-se quanto possível no lugar do outro, compreendê-lo: isso em que confiamos sempre excessivamente, isso que é como um projeto nunca alcançado, todavia faz diferença e deixa menos arbitrária nossa atenção (Gonçalves Filho, 2003).

Outros procedimentos do método etnográfico também buscaram ser seguidos. Um deles é a de integrar os conhecimentos locais à elaboração da descrição densa. Na medida do possível, as falas e as indicações dos próprios sujeitos formaram a base da descrição de uma situação analisada (Sato \& Souza, 2001). Outro ponto é a permanência por longo tempo no campo, única forma de que certos fenômenos possam ser revelados e compreendidos (Sato \& Souza, 2001). Além dessas, procuramos seguir a orientação de que a clara delimitação do objetivo do estudo e da natureza do objeto permite que o pesquisador possa lidar com as incertezas e os imprevistos da imersão no campo (Sato \& Souza, 2001). Nesse caso, o objetivo da pesquisa era responder a seguinte pergunta: a organização do trabalho fabril permite a efetiva participação dos trabalhadores no governo do trabalho assim como um envolvimento com as tarefas por meio do uso de habilidades pessoais?

Dessa forma, o objetivo desta pesquisa foi apresentar e pensar experiências de trabalho na fábrica por meio da narrativa de conversas e de episódios vividos. As observações privilegiam os momentos em que algo de substancial e marcante parecia revelar-se, seguindo indicações dos próprios trabalhadores. Tanto os diretores da fábrica, como os trabalhadores foram informados sobre a intenção da pesquisa: estudar as consequências da organização produtiva sobre a experiência do trabalho. Não houve relato de episódios que pudessem expor os trabalhadores a futuras sanções e os episódios narrados envolveram a autorização dos sujeitos assim como a alteração de seus nomes.

\section{Contextualização da fábrica pesquisada, seu sistema técnico e a experiência de trabalho}

A fábrica onde ocorreu a pesquisa é uma metalúrgica capacitada para a realização de estamparia, usinagem e serralheria industrial. $O$ número de trabalhadores no chão-de-fábrica oscilou durante a pesquisa, mas manteve a média de cinquenta trabalhadores ao longo desse tempo. Sua produção atende encomendas realizadas por outras fábricas, geralmente de médio e grande porte, também da região do $\mathrm{ABC}$ paulista. Um ponto inicial de interesse é que essa indústria situa-se em um dos últimos elos da cadeia produtiva metalúrgica: ela presta serviços diretamente para grandes multinacionais ou para fábricas menores que prestam serviços para as maiores. Dentro dessa cadeia de terceirização, ela deve ser capaz de realizar qualquer tipo de peça que lhe seja encomendada. A fábrica cliente realiza o pedido da peça enviando um desenho, e a fábrica então irá produzi-la de acordo com essa especificação. Além disso, a produção divide-se entre encomendas regulares (o mesmo número de peças é feito todo mês) e encomendas pontuais (produção esporádica de certas de peças). Durante o tempo da pesquisa observou-se uma enorme variabilidade da produção, tanto em relação à quantidade como em relação aos produtos: da fábrica partiam enormes estruturas complexas que mal cabiam nos caminhões, mas também pedaços de ferro delicadamente trabalhados que cabiam na palma da mão, tudo isso seguindo ritmos e prazos muito variados.

Essa consideração leva-nos a imaginar inicialmente uma experiência de trabalho que integra certa imprevisibilidade e, por consequência, a utilização de reflexão e criatividade para 
superar as dificuldades surgidas na realização das diferentes encomendas. Além disso, a construção de tipos muito variados de peças poderia demandar a utilização de máquinas polivalentes, com as quais o trabalhador poderia ricamente enfrentar as tarefas propostas. No entanto, as observações permitiram constatar uma contradição: apesar da maleabilidade e da flexibilidade produtivas, cristalizadas no sistema técnico, apesar das iniciativas necessárias para enfrentar diferentes problemas produtivos, a maior parte das atividades dos ajudantes gerais e das operações com máquinas exige comportamentos extremamente simplificados e repetitivos. Essa contradição inicial pode ser assim descrita: a criatividade e a maleabilidade parecem expressar-se coletivamente, no resultado do conjunto da produção, mas não em cada uma das atividades individuais. Essa observação caracteriza um campo de luta que buscaremos melhor caracterizar: a organização prevista pela fábrica imagina o sistema técnico funcionando por si mesmo, apenas incorporando "energia elétrica" e "energia humana" para animá-lo, enquanto os trabalhadores buscam submeter o fluxo racionalizado das atividades às suas iniciativas, habilidades e possibilidades de controle de tempo e de prazos de produção.

Essa impressão surgiu logo na primeira visita. O engenheiro levou-me para uma apresentação geral da fábrica: durante o longo trajeto, sua apresentação consistiu na descrição do funcionamento e da interação de cada uma das máquinas. Isto era apresentado: as máquinas funcionam e interagem desta ou daquela maneira. Os homens inicialmente parecem escondidos atrás das máquinas, dos instrumentos e das peças. Apresentar a fábrica, do ponto de vista do engenheiro, significava descrever seu mecanismo, e este encontrava-se cristalizado nas máquinas e nos instrumentos que, espalhados de maneira precisa pelo ambiente, "respondem" pelo seu funcionamento.

Um exemplo pode ajudar a compreender a realidade dessa concepção mecanicista de organização: o trabalho nas prensas. Essas máquinas podem imprimir grandes transformações em pedaços de ferro ou aço, como furá-los, dobrá-los ou repuxá-los segundo direções prédeterminadas. Na parte de cima do equipamento fica a "ferramenta", uma espécie de molde que irá determinar a transformação da peça. Essa parte é substituível, e cada tipo de peça que se deseja modelar possui sua ferramenta apropriada. Como se opera uma prensa? Apesar da infinita variabilidade de transformação que comporta (em função da troca das ferramentas), cada operador tem sempre, qualquer que seja o caso, apenas a tarefa de colocar um pedaço de ferro ou de aço no suporte inferior da máquina, acionar o início da operação, aguardar a descida e subida da ferramenta, retirar a peça e iniciar o ciclo novamente. A atividade é extremamente simples e repetitiva. $\mathrm{O}$ operador não produz a ferramenta e tampouco determina sua troca ou permanência em cada momento. A habilidade do operador é medida pela velocidade com que coloca uma peça no interior da prensa e aciona seu funcionamento. Esse esquema se repete em quase todas as outras: as que cortam, as que desgastam, as que furam, as que juntam...

A guilhotina é outro bom exemplo da simplicidade das operações exigidas pelas máquinas. Essa máquina trabalha por cisalhamento, o que significa que um grande golpe é desferido na peça por meio de uma lâmina afiada. A entrada da máquina é muito larga, permitindo o corte de grandes chapas finas de aço. Essa entrada também possui um mecanismo que impede que as mãos possam ser colocadas na área de corte. $O$ operador deve realizar movimentos muito simples: ajustar um anteparo na parte de trás da máquina, obedecendo a medida correta do corte que se pretende fazer; apoiar a chapa na frente da máquina e empurrála para dentro do mecanismo até que encoste no anteparo; apertar o pedal de início da operação na parte esquerda da máquina; continuar a empurrar e a apertar o pedal até que a chapa tenha sido consumida; finalmente, buscar outra chapa e reiniciar a operação.

As máquinas da seção de usinagem apresentam a mesma simplicidade. A principal operação ali é a de fazer furos nas peças. As máquinas dessa seção são grandes furadeiras nas quais se pode fixar o objeto no suporte inferior. As brocas que irão realizar os furos podem ser trocadas e, através de uma alavanca, determina-se a descida da broca sobre a peça. $\mathrm{O}$ suporte 
inferior possui uma morsa que permite fixar a peça, impedindo qualquer movimento que possa afetar a precisão do lugar em que o furo deve ser realizado. A alavanca permite que a broca seja empurrada contra a peça sem a utilização de muita força.

A apresentação dessas máquinas permite entender o ponto de vista da engenharia sobre a lógica do funcionamento fabril: alguns coordenadores (conhecidos como encarregados) conhecem o objeto que deverá ser produzido e ordenam aos operadores que mantenham suas máquinas em funcionamento numa determinada velocidade, utilizando certa ferramenta e certa matéria-prima. Em determinado momento, os pedaços de ferro e aço previamente manipulados pelos operadores de máquinas, com o auxílio dos ajudantes gerais, chegam até a seção de serralheria ou de solda. Nessas seções, os pedaços (previamente cortados, dobrados, furados ou moldados) serão juntados de acordo com as especificações do desenho. Essa atividade de junção compete a alguns soldadores e serralheiros, responsáveis pela "montagem" das peças utilizando a solda MIG.

A organização prescrita parece basear-se na seguinte ideia: os operadores alimentam as máquinas, são responsáveis por mantê-las em funcionamento em uma certa velocidade. Os encarregados são responsáveis pela definição das ferramentas e pela integração dos resultados parciais de cada uma das operações. Essa separação de funções está ancorada na possibilidade de troca das ferramentas em cada máquina. Isso permite que coisas, máquinas e operadores possam ser eficazmente utilizados. Em certo momento, as peças previamente transformadas pelas máquinas chegam até os serralheiros e soldadores. Eles possuem o desenho da peça, com especificações dos ângulos e das formas das junções. Ainda assim, apesar de participarem de uma maneira diferenciada da elaboração do produto, a atividade desse grupo sofre fortes pressões geradas pela intensidade da produção: quando são muitas peças (como é a maioria dos casos), dividi-se o trabalho e monta-se um "molde" na mesa da seção, permitindo que o trabalho seja feito a toda velocidade e de uma forma repetitiva, lembrando a operação das máquinas. O molde é uma espécie de forma na qual se encaixam as partes da peça para que não seja necessário medir e ajustar o ângulo em cada operação: simplesmente encaixa-se e solda-se rapidamente.

A análise feita por Braverman sobre o significado da revolução técnico-científica parece encontrar correspondência com o que foi observado: o papel do fator subjetivo é diminuído, seu lugar no processo de trabalho é "transferido para um lugar entre os fatores objetivos inanimados" (Braverman, 1981). Neste caso específico, para as ferramentas e as relações entre elas. Além disso, como afirma Braverman, em conjunção com as exigências das operações, existe a tentativa de tratar os trabalhadores como máquinas, seja em função da objetivação de seus comportamentos (os movimentos são prescritos como complementares ao funcionamento veloz das máquinas), seja em função do regime de ordens (não há campo previsto para iniciativas além das necessárias para manter a velocidade produtiva). Os comportamentos passam a ser efetivamente medidos em função dos resultados produtivos que podem ser alcançados junto às máquinas.

Ainda assim, a experiência de campo indica que a exclusão do fator subjetivo no trabalho expressa um aspecto da questão e precisa ser relativizado. A descrição do sistema técnico apresenta uma arena onde uma série de conflitos e formas de resistências encontram lugar. O sistema produtivo solicita iniciativas dos trabalhadores e eles encontram formas sutis de singularizar suas atividades. Criam-se formas astuciosas de transformação das condições prescritas de trabalho que atendem necessidades dos sujeitos envolvidos (Sato \& Oliveira, 2008). Essas formas, apesar de se adaptarem ao imperativo da aceleração da velocidade produtiva, dialogam com a necessidade de encontrar posturas mais cômodas de trabalho, de proteção frente aos perigos das tarefas, de instaurar a possibilidade de conversas com colegas, formas de proteção (individuais e coletivas) contra acidentes ou simplesmente permitirem a expressão de certas habilidades pessoais. 
Alguns episódios de campo são ilustrativos a respeito das formas astuciosas de resistência ao trabalho racionalizado. A primeira tarefa que me coube foi a de lixar peças. Deveria lixar pequenos pedaços retangulares de ferro retirados de uma caixa, eliminar as rebarbas, aplainar as arestas. Deve-se gastar a peça contra a lixadeira, uma esteira que fica rolando muito rapidamente, com comprimento aproximado de um metro, posicionada horizontalmente à altura da barriga. Era aparentemente simples: empurrar peças, uma atrás da outra, contra essa esteira. Comecei o trabalho e a tarefa que parecia simples revelou uma certa complexidade: pode-se facilmente deixar a peça escapar, dependendo do movimento que se faz e por onde se segura a peça. Neste caso, a peça voa, é atirada para longe, ficando apenas a perplexidade sobre o que aconteceu e a vergonhosa sensação de inabilidade. Além disso, a mão pode ir de encontro à lixa com toda a força que se esperava entregar à peça, o que pode acarretar um acidente. Tendo visto isso, um dos trabalhadores aproximou-se e disse: "olha, para fazer isso aqui é melhor segurar assim, por cima, e raspar ela contra o movimento da lixa, no sentido contrário, assim ó....". Mostrou-me. Era um gesto preciso, combinando a força exigida e a direção correta. Ofereceu-me sua luva de couro para que eu protegesse minha mão e, a partir dali, soube que podia contar com ele para pedir ajuda. Seu gesto assumiu para mim, em meio às forças e aos riscos, sentido fraterno inegável. A solidariedade nos apuros aproxima, leva a conversar, parece imediatamente apoiar alguma amizade.

A iniciativa de oferecer ajuda, a luva de couro emprestada, a maneira como ensinoume a realizar o trabalho, a pequena conversa de apresentação depois da dificuldade remediada, todo esse pequeno episódio já encerrava traços que seriam multiplicados sob diversos aspectos durante a experiência prolongada na fábrica: as iniciativas de comunicação e de trocas, o apreço por isso, a afirmação de um saber singular que torna mais fácil e pessoal a tarefa penosa e anônima, a solidariedade, a atenção dirigida ao outro. Aquele simples primeiro encontro continha em si como que um primeiro exemplo de experiências relacionadas àquela organização do trabalho. A ajuda e a proteção inesperadas, o ensinamento de uma forma de trabalhar (observamos formas diferentes de trabalho com a lixadeira e com outras máquinas), tudo isso já apresentava um anúncio do sofrimento e da resistência na fábrica. A compreensão das atividades, as possibilidades de participação na realização do trabalho dependem da entrada numa rede de relacionamentos que se forma entre os operários no chão-de-fábrica. Seria por demais difícil trabalhar em uma fábrica sem amigos feitos ali. Uma das formas de resistência ao sofrimento cotidiano parece nascer da amizade que, sutilmente, quase despercebidamente, penetra e compensa o fardo do trabalho repetitivo. Em diversos casos, essa rede também permite a antecipação e a resolução de problemas produtivos sem a dependência dos encarregados, o que se mostra como sendo ao mesmo tempo um fator essencial para a continuidade produtiva.

Outro episódio pode servir de exemplo para ilustrar o conflito entre o ambiente racionalizado e as necessidades de participação e de preservação de habilidades pessoais. Em certa ocasião, um dos pintores fazia a chamada pintura "prime" em um conjunto de peças. $\mathrm{O}$ encarregado aproximou-se e o repreendeu por estar fazendo o trabalho com um cuidado desnecessário, aumentando muito o tempo de cada pintura. $O$ trabalhador não escutou passivamente: respondeu que aquela era a maneira correta de se realizar a pintura. Seguiu-se uma discussão entre os dois e o pintor argumentou a favor de seu método, dizendo o seguinte: "Você quer que eu faça o serviço? Eu vou fazer da minha maneira. Do jeito que você quer que eu trabalhe, eu não vou trabalhar. Eu sou um profissional. Se vocês querem que eu faça qualquer coisa, eu estou indo embora". O encarregado saiu contrariado e pouco depois o chamou para uma reunião em sua sala. Apesar de repreendê-lo pela resposta, tolerou a forma e o tempo de trabalho do pintor.

Os trabalhadores, principalmente os soldadores, serralheiros, pintores e operadores de torno $\mathrm{CNC}^{2}$, não agem apenas em função das ordens dos encarregados nos momentos em que 
param, pedem ou oferecem ajuda, trocam de atividade, esperam ou concentram-se em outro ponto da produção. A movimentação dentro da fábrica é complexa, não se pode reduzir apenas às ordens dadas pelos encarregados. Isso significa que a observação de campo sustenta a hipótese de que o funcionamento da fábrica depende das iniciativas tomadas pelos operários na resolução de problemas, na ajuda oferecida a outros companheiros, na coordenação que realizam de suas próprias atividades. Observa-se, confirmando uma ideia apresentada por Leny Sato (2002), uma negociação cotidiana de pedidos de ajuda, de empréstimos de instrumentos, de organização das atividades, de utilização dos espaços comuns, que têm como objetivo o estabelecimento de acordos que possam favorecer os sujeitos implicados, configurando situações de trabalho às vezes diferentes das condições prescritas (Sato, 2002). As negociações relacionadas aos oferecimentos e aos pedidos de ajuda (que revelaram certo código compartilhado por todos em relação ao tema) eram justificadas também pela possibilidade de aliviar o tédio implicado na repetição das atividades. Como afirmou certa vez um trabalhador: "a gente troca também entre a gente, ajuda os outros, para poder aguentar mais o trabalho". Em cada troca, em cada oferecimento de ajuda, em cada pedido, uma conversa, a voz e o rosto do outro. Esse mesmo operário disse que as iniciativas de ajuda eram incentivadas pela fábrica, pois ao mesmo tempo ajudavam o funcionamento da produção.

Esses episódios permitem observar melhor o campo de luta: existe uma significativa redução da participação do trabalhador na definição de sua atividade, mas isso não significa que a subjetividade não apareça de várias outras formas nas relações de produção, expressa como resistência, organizada de forma mais pessoal ou coletiva, ou como forma de lidar com o sofrimento gerado por essa organização do trabalho. Principalmente, buscando mitigar a sensação de falta de controle do tempo e de dispensabilidade constante objetivadas pela concepção técnica do trabalho.

Observando a existência de um campo de luta entre os interesses racionalizados da produção e as necessidades de participação dos trabalhadores (expressão de habilidades pessoais e formas de controle do tempo produtivo), podemos melhor descrever os fatores que levam ao sofrimento ligado ao trabalho. Não são apenas aqueles ligados à separação entre concepção e execução do trabalho (esvaziando o sentido da atividade, gerando fadigas e adoecimentos por esforços repetitivos). O sofrimento gerado pelo trabalho também está ligado à naturalização das incertezas no vínculo trabalhista e à individualização dos conflitos. Sem dúvida, o maior fator gerador de sofrimento liga-se à racionalização das atividades, mas isso não se faz apenas por meio da separação técnica entre concepção e execução das atividades. A necessidade de cumprir os prazos impostos pelas fábricas clientes, a rotatividade de mão-deobra ligada às oscilações da intensidade produtiva, a imposição de uma auto-organização dos grupos, todos esses fatores determinam que a instrumentalização seja internalizada. O fato é que todos sabem que se não forem utilizados velozmente pela produção e não ajudarem a fábrica a atender os prazos variáveis das encomendas, seus postos de trabalho correm riscos.

Esse contexto permite entender a polêmica existente entre dois sociólogos marxistas, Michel Burawoy e Harry Braverman, em relação ao estudo do sofrimento gerado pelo trabalho. A observação do sistema sócio-técnico da fábrica pesquisada permite confirmar a tese de Braverman (1981) segundo a qual o desenvolvimento das máquinas tem como objetivo aumentar o controle sobre o processo produtivo e, portanto, também sobre a atividade do trabalhador a ele incorporado. Isso determina formas de sofrimento que buscaremos descrever adiante. Ainda assim, é preciso observar que, no limite, a execução simples e pura da prescrição inviabiliza o próprio processo produtivo e, quanto mais uma fábrica é capaz de adaptar-se rapidamente às contingências de mercado, tanto mais necessita de um alto grau de adesão e de iniciativa dos trabalhadores. $\mathrm{O}$ aspecto político da organização do trabalho torna-se então fundamental para explicar essa adesão. De qualquer forma, está caracterizado um campo de conflito: por um lado, a pressão fabril para que os trabalhadores tomem iniciativas com o 
intuito de aprimorar o seu próprio "uso racional"; por outro, a manutenção e aplicação de saberes coletivos protetores de uma dignidade do trabalho.

$\mathrm{Na}$ descrição de Braverman, a exploração do trabalho segue uma linha evolutiva: de um ponto onde o trabalhador controlava seu trabalho em direção a um ponto onde ele se torna praticamente um instrumento da produção. Para Buroway, a questão é saber como a mais-valia é simultaneamente garantida e escamoteada, e a compreensão desse fenômeno envolve a investigação dos processos políticos no próprio chão-de-fábrica, entender como as pessoas coletivamente validam ou, então, resistem e transformam as relações de produção (Buroway, 1990). Exatamente por isso torna-se necessário investigar as novas formas de treinamento, avaliação e gestão do trabalho, buscando-se pensar como têm refletido no processo de adesão ou no enfrentamento das condições de trabalho por parte dos trabalhadores.

O campo de luta pode assim ser caracterizado: a divisão do trabalho determinada por essas máquinas não parece acompanhar a existência de diferentes talentos ou habilidades, mas, sim, acompanhar a simples necessidade de fragmentar as atividades e acelerar a cadência da produção. Diante dessas máquinas, o sentido do trabalho é reduzido a mantê-las em rápido funcionamento. Essa eficácia é efetivamente medida pelos encarregados: existe uma quantidade de peças prontas que se espera dos trabalhadores em um determinado intervalo de tempo. Foi possível observar ocasiões em que as peças de um operador eram contadas, ou então, o cronômetro era utilizado pelos encarregados para avaliar a produtividade. Muitos trabalhadores relataram que as exigências de produtividade determinavam que as atividades fossem realizadas em um ritmo extenuante. Um dos aspectos geradores de sofrimento no trabalho fabril é o fato de que o trabalhador é avaliado pela velocidade de seus gestos e, caso as metas impostas não sejam alcançadas, sua permanência na fábrica está ameaçada.

Observamos inicialmente uma diferenciação em três escalas no que se refere à qualificação (aqui entendida como possibilidade de aplicação de conhecimentos, de utilização de algum tipo de reflexão e da manutenção de alguma autonomia na realização da tarefa): os ajudantes gerais (responsáveis por operações acessórias), os operadores de máquinas e um terceiro grupo composto pelos serralheiros, pintores e soldadores. Essa diferenciação tem profundas implicações no chão-de-fábrica: além de instaurar uma constante esperança por parte dos operadores e dos ajudantes de chegarem a ser operários mais qualificados, também permite uma grande rotatividade de trabalhadores dentro dos dois primeiros grupos. $O$ trabalho simplificado permite que um novo trabalhador aprenda sem dificuldade e com grande rapidez a operação das máquinas. Em certos momentos, também existe uma competição no interior dos grupos para se definir quem subirá de degrau, situação que resulta em um ganho significativo de produtividade para a fábrica. Efetivamente, a rotatividade de mão-de-obra foi maior no grupo de ajudantes, um pouco menor no grupo de operadores e praticamente inexistente no terceiro grupo, durante o tempo da pesquisa. O sistema técnico parece ser montado para possibilitar a troca rápida e fácil dos operadores e, com isso, diminuir o poder de barganha desse grupo.

A generalização dessa forma de organizar o trabalho tem como resultado um incremento da velocidade de produção. Mas quais são os resultados para a experiência de trabalho? Os pontos que nos chamaram a atenção foram os relatos de tédio, de grande cansaço e, em alguns casos, de uma espécie de sono ou transe vivido em algumas atividades repetitivas. O exemplo mais claro disso é o trabalho na prensa. A movimentação rígida e repetitiva do corpo inteiro em alta velocidade pede uma coordenação que, para ser mantida, supõe não sermos "perturbados" pelo pensamento. Não se pode olhar para o lado ou conversar enquanto se trabalha com a prensa, pois essas atitudes desconcentram o corpo e diminuem sua velocidade, quando não exigem que pare completamente. A atenção é aqui absorvida pela manutenção de um corpo-máquina em funcionamento, pela manutenção de sua cadência e repertório gestual. Isso determina um enorme cansaço mental, como foi descrito por um dos operadores: "ao final do dia você está acabado, não consegue pensar em nada, só quer saber de dormir!". 
Algumas observações dos trabalhadores indicavam que o custo de adaptação às exigências das atividades é sobretudo corporal. Quando discutiam a entrada de uma nova encomenda, observando que isso acarretaria um aumento da cadência, sempre concluíam: "mas o corpo se acostuma". Quando mencionavam como era ruim a segunda-feira, porque era preciso voltar a trabalhar depois de um período de descanso no qual o corpo desacostumava-se com as atividades, também acrescentavam: "mas o corpo se acostuma". Essa frase pode ser entendida como descrição rigorosa de uma experiência: quando se aumenta a quantidade e o ritmo de trabalho, é o "corpo em funcionamento" que se acostuma. Jamais diriam que "alguém se acostuma", nunca "a gente se acostuma".

Uma das consequências da experiência de trabalho, em alguns casos, parece ser uma forte sonolência surgida durante a realização das atividades. $O$ operador da guilhotina disse-me certa vez: "rapaz, fazer isso aqui é tão chato, mais tão chato, que chega a dar um sono!". Contou-me isso em um dos intervalos de sua operação. Alguns outros operários também relataram essa espécie de sono durante a realização monótona e repetitiva de suas atividades: alguns trabalhadores da serra-fita, da lixadeira, entre outros. Esse sono apontado pelos operadores parece descrever uma experiência intimamente relacionada aos movimentos e à atenção exigidos pela tarefa, reflexo de uma atitude meramente contemplativa frente ao funcionamento da máquina. Em muitos casos também é um sono temido, que assombra cada trabalhador com a possibilidade de trazer consigo as condições para um acidente.

Durante várias conversas com trabalhadores, muitos deles contaram de um aspecto não muito visível do sofrimento gerado pela organização do trabalho: a realização de horas extras com a fábrica vazia. Enfatizavam que o aspecto negativo era o cansaço, mas também o isolamento, não poder encontrar ninguém, não estar com alguém por perto. Essas falas revelavam um sentido das negociações cotidianas: elas permitiam encontros e conversas que de certa forma eram sancionadas pela fábrica, porque também permitiam que o trabalho fosse melhor realizado. Há uma confluência de interesses nessas negociações: permitir interromper o fluxo repetitivo e monótono de gestos para encontrar um colega, assim como prevenir ou resolver imprevistos que poderiam comprometer a produção. Além disso, as negociações tinham uma importante tarefa de proteger os trabalhadores. Presenciamos a existência de um código de ajuda presente no chão-de-fábrica, respeitado por todos, inclusive encarregados. A qualquer momento em que um trabalhador se encontrasse em apuros, em função de uma dificuldade surgida durante a tarefa, os mais próximos prontificavam-se em prestar ajuda. Essas dificuldades surgiam muitas vezes nos difíceis transportes das peças de uma seção para outra, mas também em diversas ocasiões imprevistas. Quando as dificuldades eram previsíveis, as ajudas eram negociadas anteriormente à execução da tarefa. Muitas outras formas de negociações foram observadas: negociações de instrumentos, de prazos de entrega do trabalho junto aos encarregados e até mesmo de atividades e postos entre os trabalhadores.

Todas essas negociações significam mais do que apenas uma forma de lidar com os imprevistos do trabalho: elas representam também um meio de integrar-se a uma teia de relações estabelecidas entre os trabalhadores no chão-de-fábrica que tem como principal objetivo abrigar o que de humano foi excluído da organização estritamente estabelecida pelo sistema técnico. As negociações cotidianas representam uma forma de proteção dos trabalhadores frente aos efeitos de um ambiente racionalizado e impessoal. A fábrica exige que cada operário esteja constantemente à disposição de suas exigências em função das encomendas que chegam e saem, às vezes inundando de trabalho uma sequência produtiva, retirando trabalho de outras, às vezes modificando substancialmente as características e as cadências das atividades. Essa característica da organização do trabalho determina uma associação angustiante entre a monotonia das movimentações repetitivas e as transformações abruptas e imprevisíveis das condições de trabalho. Isso coloca a todos frente a dois tipos de ameaças: estar sem lugar na produção, o que acarreta a ameaça de dispensabilidade, ou então o mergulho na repetição estéril de gestos e movimentos que congela o próprio tempo. Dessas 
duas ameaças os trabalhadores buscam defender-se fazendo com que os relacionamentos que se estabelecem entre eles possibilitem não expor nenhum operário a uma situação de falta de lugar e tampouco deixar que a ocupação de um lugar termine por absorvê-lo completamente.

\section{O trabalho e seu fluxo tensionado}

Apesar da flexibilidade em relação aos tipos de produtos e aos prazos de entrega, a discussão acima permite observar que o sistema técnico da empresa em questão é fundamentalmente taylorista. No entanto, essa fábrica faz parte de uma cadeia produtiva na qual o fluxo tensionado é determinante. $\mathrm{O}$ fato de que a fábrica pesquisada atenda encomendas de fábricas maiores a coloca em um dos últimos elos da cadeia produtiva. Dentro da atual organização reticular da cadeia produtiva, sua posição é periférica. Isso teria consequências sobre a experiência de trabalho? O material recolhido indica que sim. A principal pergunta é como o sistema de fluxo tensionado de produção afeta a experiência de trabalho em uma empresa periférica.

Durante o tempo da pesquisa, a fábrica oscilou entre períodos de altas encomendas e de baixas encomendas, sem que fosse possivel realizar uma previsão ou planejamento dessas oscilações. No início da pesquisa, o momento era de baixa produção. Todos os trabalhadores estavam extremamente preocupados com a manutenção de seus empregos. Os que ficavam em certos momentos sem tarefas, expressavam intensa angústia. Os trabalhadores passaram a dividir espontaneamente trabalho com seus colegas que não tinham o que fazer. Passou a ocorrer intensa negociação de postos de trabalho. Os encarregados não se intrometeram no assunto, pareciam preferir olhar todos ocupados, mesmo que dividindo tarefas, do que observar alguém sem atividade. Nesse período era evidente a preocupação dos trabalhadores: se aquela situação continuasse, ocorreria o "facão" brevemente. Todos torciam para que a produção aumentasse e as novas encomendas chegassem. $\mathrm{O}$ importante de reter inicialmente: todos os trabalhadores sabem que a fábrica realiza ajustes periódicos do número de trabalhadores de acordo com seus momentos produtivos e, excetuando-se certo núcleo reduzido de trabalhadores mais qualificados e estáveis, todos estão ameaçados constantemente pela oscilação da intensidade produtiva. O risco desse tipo de organização produtiva é repassado aos trabalhadores. A rotatividade da mão-de-obra nessa fábrica é grande: durante os dois anos de pesquisa, mais de um quarto da mão-de-obra foi totalmente renovada nesses movimentos de demissão e admissão. Vamos ilustrar esse movimento com a descrição de um episódio.

De repente, durante aquele momento de baixa produção citado, chega aos trabalhadores a informação de que a fábrica tinha fechado uma grande encomenda. Ela passaria a funcionar em três turnos completos (manhã, tarde e noite). Ao mesmo tempo em que isso despertou um alívio, todos também ficaram inseguros com as transformações imprevisíveis que ocorreriam no chão-de-fábrica. Como seria o novo trabalho? Haveria horas extras? Haveria alteração de postos? De um dia para o outro, o encarregado comandou a elaboração de uma enorme mesa de produção, que ocupava quase metade da largura da fábrica. Naquela mesa ficariam os novos postos de trabalho. As tarefas mostraram-se extremamente simples e as peças eram passadas de um trabalhador a outro até o final da mesa. Mas a surpresa seria ainda maior: a fábrica "terceirizou" a contratação dos novos funcionários para atender a algumas necessidades produtivas dentro da fábrica. Uma empresa prestadora de serviço iria realizar parte da produção, mas no interior da fábrica. Isso gerou grandes conflitos: os trabalhadores antigos foram hostis em relação aos terceirizados, provavelmente porque sentiram seus empregos ameaçados por esse grupo. Todos sabiam que a encomenda teria duração de seis meses e, após esse período, as demissões seriam inevitáveis. Mas havia um temor não formulado de que, se algum trabalhador novo mostrasse melhor desempenho, ele poderia ficar com a vaga 
de um antigo. Os trabalhadores "terceirizados" encaravam aquilo como um estágio em que seria preciso sacrificar-se para conseguir a efetivação. Isso gerou muita irritação entre os antigos e a competição ficou explícita: os antigos não conversavam com os novos, no refeitório estes eram obrigados a sentar no chão, pois não havia lugar para todos. Nas brincadeiras dos intervalos de almoço não havia a menor integração: os antigos usavam o espaço da fábrica para jogar pinguepongue ou dominó no refeitório, enquanto os novos sentavam na calçada do lado de fora da fábrica. Os antigos encontravam motivos recorrentes para se queixarem com os encarregados das atitudes dos novos. A competição entre os trabalhadores estava instalada, com grande beneficio para a fábrica. As consequências da frustração gerada pela falta de segurança no trabalho foram dirigidas a outro grupo de trabalhadores e não à análise do contexto produtivo, o que poderia gerar outras formas de reação.

Outros elementos encontrados dessa organização da fábrica a caracterizam dentro do modelo de fluxo tensionado apresentado por Durand (2003). Na fábrica havia sido abolido o cargo de inspetor de qualidade, e todos os funcionários eram responsáveis por avaliar a qualidade das operações feitas antes de entregar as peças para o encarregado. Isso determinou um aumento da responsabilidade individual na entrega do serviço. Ao mesmo tempo, não houve nenhuma alteração efetiva das atividades além do controle que cada um deve realizar sobre sua própria produção.

A maior parte das encomendas pontuais de peças era feita dentro de prazos que obrigavam os trabalhadores a realizarem muitas horas extras e a trabalhar em um ritmo muito intenso. A entrega just-in-time de encomendas fazia-se sentir dentro de um mesmo dia de trabalho: às vezes, a equipe de pintura não tinha trabalho pela parte da manhã e precisava, segundo palavras dos próprios trabalhadores, "caçar trabalho". Mas, inesperadamente, ao final da tarde chegava uma encomenda que deveria deixar a fábrica no dia seguinte e, então, era preciso fazer horas extras, algumas vezes noite adentro. Isso foi revelado pelos trabalhadores como fonte de intenso sofrimento: a realização de horas extras, o ritmo intenso e a impossibilidade de planejamento do trabalho. Essa impossibilidade fazia com que os trabalhadores sentissem que estavam submetidos a certos determinantes incontroláveis de tempo de trabalho.

Um fator importante da organização do fluxo tensionado é a aparente autonomia oferecida aos trabalhadores. Confirmando a análise exposta por Durand, essa suposta autonomia é uma tática para escamotear o conflito entre capital e trabalho e forjar o conflito entre os próprios trabalhadores. O grande mérito organizacional do modelo do fluxo tensionado, para a gerência, é aumentar a competição e diminuir a cooperação entre os trabalhadores, conseguindo muito mais eficazmente a adesão deles aos objetivos da empresa. Seguindo o exemplo da equipe de pintura: o encarregado informa à equipe a chegada da nova encomenda, determina como o trabalho deve ser feito e qual é o prazo. A equipe tem certa "autonomia" para se dividir e realizar a tarefa. Dentro de certos limites, respeitados pelos cargos de cada um, eles podiam decidir como dividir o trabalho, quem iria fazer horas extras e quem não. Muitas vezes isso gerava grandes conflitos. Sempre escutava acusações de que na divisão alguém queria ficar com a melhor parte, que alguém estaria fazendo "corpo mole" ou que o outro é que deveria ficar com as horas extras. A raiva e a frustração em função dos ritmos imprevisíveis eram dirigidas a algum colega que era visto como protegido do encarregado ou, então, que se esforçava menos na realização das tarefas. Como expõe Jean Pierre Durand, efetivamente aumenta a pressão dos pares sobre o indivíduo:

A organização e a responsabilidade coletivas no grupo de trabalho aumentam as pressões dos pares sobre cada indivíduo: atrasos, ausências repetidas, cansaço ou fracas performances não são mais dependentes ou invocadas pelo chefe, mas pelo grupo, que pode ver suas performances reduzidas ou parte do trabalho aumentar, caso um dos elementos não respeite a norma média estabelecida no grupo e por ele (2003, p. 149).

Observamos no contexto de uma empresa periférica, que alimenta as grandes indústrias 
com peças, características do modelo de fluxo tensionado de produção. Nesse contexto, tudo indica que a fábrica não planejou uma mudança organizacional na direção do modelo toyotista. Antes, ela parece ter mesclado elementos tayloristas, dentro de uma forma de produção discreta, com formas de gestão que permitiram uma adaptação às exigências do fluxo tensionado da produção, sendo estas últimas impostas pelas fábricas maiores. Como exemplo disso, podemos citar a multifuncionalidade: essa fábrica não apresentava células de produção, mas muitos trabalhadores sabiam operar diversas máquinas, em função das grandes alterações de tipos e de quantidades de encomendas. Ainda assim, em cada momento de produção, cada trabalhador operava uma máquina exclusivamente. Uma espécie de multifuncionalidade ocorria dentro de um quadro onde existe um operador para cada máquina ou operação.

O essencial do modelo de avaliação por competência também parecia ser aplicado sem que isso fosse algo planejado. Como expõe Durand (2003), esse modelo transforma-se em um meio de submissão dos trabalhadores às exigências da organização, uma vez que os critérios de promoção tornam-se mais arbitrários e menos objetivos. Alguns trabalhadores queixavam-se de que não eram "promovidos" simplesmente porque não realizavam tudo que lhes era pedido pelo encarregado. A resistência em realizar, por exemplo, horas extras segundo a vontade da fábrica determinava que alguns trabalhadores tivessem seus salários congelados, enquanto alguns que tinham chegado havia menos tempo já ganhavam mais simplesmente por serem "colaboracionistas". Isso também alimentava competições e discórdias entre os operários mais críticos e os que procuravam atender todas as demandas da empresa.

Nesse contexto produtivo encontramos grande insegurança dos trabalhadores em relação à manutenção de seus postos, ligada à oscilação da intensidade produtiva e à rotatividade da mão-de-obra. Essa gestão do fluxo tensionado termina por conseguir um resultado importante: a naturalização dos constrangimentos (Durand, 2003). É naturalmente preciso aceitar os prazos de entrega de peças, ou então perde-se a empresa cliente e o trabalho. É naturalmente necessário empenhar-se ao máximo, com o máximo de qualidade, ou então perde-se a confiança da empresa cliente. É natural colaborar com a empresa se o trabalhador espera melhorias em seu salário e posição. As frustrações geradas pela insegurança, pelo baixo salário, pelo esforço e pelo cansaço são administradas de forma a dificultar que se transformem na base de alguma união entre os trabalhadores em oposição aos interesses da fábrica. Poderíamos acrescentar a esse contexto de fluxo tensionado na periferia do capitalismo mais três elementos importantes: a baixa incorporação de inovações tecnológicas na produção (a maioria das máquinas são antigas, compradas de fábricas maiores, com exceção de poucas máquinas de comando numérico computadorizado), a ausência de filiação dos operários ao sindicato e a origem rural da maioria deles. Todos esses elementos em conjunto possuem forte influência sobre a formação de uma identidade profissional e de classe. A gestão do fluxo tensionado na periferia do capitalismo apresenta particularidades que merecem uma investigação mais aprofundada.

\section{Conclusões}

Encontramos no livro Manuscritos econômico-filosóficos de Marx algumas indicações que permitem ainda hoje compreender aspectos do sofrimento gerado pela organização do trabalho fabril. O trabalhador recebe trabalho - e esse termo é utilizado por Marx para caracterizar a interceptação da energia criativa do trabalhador - para revelar como a passividade e a insegurança marcam decisivamente a experiência de trabalho no modo de produção capitalista (Marx, 2004). Observamos na pesquisa de campo o constante medo em relação à manutenção do emprego, a constante imprevisibilidade dos movimentos de encomendas e o desconhecimento das relações da fábrica pesquisada com as fábricas clientes. As iniciativas 
tomadas no chão-de-fábrica, tão necessárias para o andamento produtivo, não mudam o fato de que não se controla prazos, muitas vezes não se conhece as peças produzidas e não se sabe quais serão as medidas da fábrica para adaptar sua força-de-trabalho à situação presente de encomendas. $\mathrm{O}$ conceito de reificação, cunhado por Lucaks, ainda descreve um fenômeno psicossocial ligado ao trabalho: o impacto da absorção do homem, de suas atividades, de sua vida produtiva, a um esquema geral de cálculo racional, a partir do qual sua utilização pela organização pode se justificar ou então decidir sua dispensabilidade (Lucaks, 2003). Toda ação produtiva é justificada por meio de um cálculo econômico preciso, e as atividades dos trabalhadores são planejadas em termos de máxima rentabilidade. As cobranças constantes por produtividade muitas vezes impõem ao trabalhador uma auto-objetivação. Esse contexto tem profundas implicações para os trabalhadores: sentem-se impelidos a justificar sua utilização racional e ao mesmo tempo criar formas de não serem absorvidos por esse contexto. Isso foi observado num duplo movimento: nos momentos de baixa produção, os trabalhadores começavam a dividir atividades com companheiros para que todos fossem "utilizados", pois permanecer sem atividade era algo gerador de extrema angústia; nos momentos de alta produção, uma série de iniciativas e de trocas de ajuda tinham o sentido de retirar cada um do mergulho na repetição estéril de movimentos.

As observações sobre o funcionamento da fábrica permitem concluir que uma indústria de produção discreta (aqui entendida como uma indústria capaz de adaptar-se à demanda flutuante, tanto em relação a prazos como em relação a tipos de produtos) pode perfeitamente basear a organização do trabalho na separação entre concepção e execução das atividades, em formas rígidas de imposição de prazos, tempo e atividades. O sentido das tarefas dos ajudantes gerais e dos operadores de máquinas reduz-se na maior parte do tempo a alimentar máquinas e mantê-las em rápido funcionamento. Em muitos casos, os trabalhadores desconhecem o produto que está sendo feito e não têm nenhum controle sobre as trocas de ferramentas e sobre as alterações e as flutuações de produção. Essa separação reflete-se em uma diferenciação em quatro níveis quanto à posição entre aqueles a quem cabe a execução do trabalho: 1) os ajudantes gerais, responsáveis pela realização de transportes das peças ou atividades meramente acessórias, trabalhando sob constantes ordens; 2) os operadores de máquinas, responsáveis por manter as máquinas em funcionamento, alimentando-as em alta velocidade; 3) os serralheiros, soldadores e pintores, responsáveis por confeccionar as peças e pintá-las; 4) os encarregados, responsáveis pelas trocas de ferramentas das máquinas e pela coordenação de todas as atividades no chão-de-fábrica. Essa separação entre concepção e execução das atividades gera entre os trabalhadores sofrimentos ligados ao tédio e ao esvaziamento de sentido das atividades. Gera também grande desgaste físico e as condições de adoecimento em função das atividades simples e repetitivas feitas em alta velocidade.

A necessidade de produzir em alta velocidade alia-se a formas de vigilância e de controle. A vigilância sobre os tempos e os resultados do trabalho realiza-se cotidianamente por meio da estipulação de uma quantidade de produção a ser atingida e algumas vezes até pelo uso de cronômetros. Pouco espaço foi observado para a participação do trabalhador na gestão do trabalho: os produtos são muitas vezes desconhecidos, as oscilações produtivas são incontroláveis, a definição de tempos ou de prazos é feita pela gerência ou imposta pela fábrica cliente. Essas conclusões empíricas reforçam a percepção de uma contradição irremediável nos textos dos que defendem avanços nas novas formas de organização do trabalho fabril: a necessidade de enfrentar a concorrência, reduzindo custos e aumentando velocidade de produção, termina por ser incompatível, no chão-de-fábrica, com verdadeiras melhorias das condições de trabalho.

Ainda que este estudo de caso não se refira a uma indústria que adote o modelo japonês, as observações levam-nos a pensar algumas contradições que aparecem nos textos dos divulgadores da forma de produção toyotista: por exemplo, ao mesmo tempo em que afirmam que esse sistema "recupera a tradição do trabalho artesanal de englobar cabeça e mãos no 
processo produtivo, que havia sido destruída pelo sistema taylorista-fordista" (Ferro, 1990), afirma também que seria preciso "eliminar totalmente desperdícios de materiais, pessoal, movimentos"(Ferro, 1990, grifo nosso). Salienta dois outros pontos nitidamente contraditórios com a ideia de superação do taylorismo-fordismo: o primeiro é que "a simplificação do trabalho é fundamental para garantir a sincronização, facilitando o aprendizado dos trabalhadores e a rotação entre diferentes tarefas" e que nesse sistema "os ciclos de trabalho, o tempo para cada operação, tendem a ser bastante reduzidos e a sequência de trabalho definida através da utilização das tradicionais técnicas de tempos e métodos". A única diferença é que essa definição seria feita "em conjunto com os trabalhadores, com muitas tentativas e modificações, sempre sujeito a melhorias dentro do princípio do Kaisen". Tentar transformar o trabalhador em aliado da empresa na construção da simplificação e na definição dos tempos não significa superar efetivamente o padrão taylorista-fordista. $O$ que observamos nesta pesquisa e na revisão bibliográfica é que as sugestões são aceitas na medida em que melhorem (diminuam) o tempo de produção, e não na medida em que melhorem as condições de trabalho. $\mathrm{O}$ conflito capitaltrabalho em uma economia de livre mercado não criará por si mesmo um contexto de formação de melhorias nas condições de trabalho, a não ser que isso ocorra por meio de um embate e da reivindicação coletiva e organizada da classe trabalhadora.

As pesquisas recentes sobre a organização do trabalho fabril, juntamente com uma análise rigorosa dos textos de propaganda sobre o modelo japonês, indicam que o taylorismofordismo como paradigma de gestão não foi efetivamente superado, mas aperfeiçoado. Como podemos observar na tese de Márcia Hespanhol Bernardo, esse modelo de gestão do trabalho não se configura como superação do padrão taylorista-fordista, mas como a inclusão dos saberes e da inteligência dos trabalhadores no sentido de aprimorar os objetivos do antigo sistema (Bernardo, 2006). Isso, portanto, significa considerar que ocorreram transformações no modo de gestão, mas que elas se deram sobre a base da manutenção e do aprimoramento dos objetivos do paradigma taylorista-fordista. Como havia sido exposto por Michael Buroway já em 1985, no livro Politics of production, as fábricas começaram a perceber que a aplicação até as últimas consequências do taylorismo seria prejudicial, principalmente por perder as iniciativas dos trabalhadores no sentido de melhorar sua própria exploração e por expor demasiadamente o conflito entre capital e trabalho (Buroway, 1990).

Exatamente devido ao fato de que as mudanças organizacionais ocorreram sobre a base de uma separação entre concepção e execução do trabalho, assim como buscavam aumentar a intensidade da produção e reduzir custos, podemos observar também que as pesquisas que buscam alcançar as vivências dos trabalhadores no chão-de-fábrica possuem um elemento comum. Como afirma Márcia Hespanhol Bernardo (2006) a respeito das experiências dos trabalhadores nas montadoras japonesas instaladas no Brasil:

As vivências dos trabalhadores discutidas neste capítulo indicam que o discurso apresentado por autores da área de gestão empresarial na atualidade - que busca mostrar uma valorização dos trabalhadores e uma maior humanização do trabalho em relação aos modelos anteriores - está distante daquilo que é vivenciado no cotidiano do chão-defábrica. Os mecanismos de controle utilizados - possibilitados, sobretudo, pela força da ameaça de demissão - são vivenciados pelos trabalhadores como formas de violência: violência psicológica, no caso das "pressões" e das "humilhações" cotidianas, e violência física, no caso da imposição de um ritmo de trabalho "insuportável" (p. 185).

Isso se assemelha muito às análises realizadas pelos trabalhadores desta pesquisa: "enquanto você tiver dando a produção, está tudo bem, mas se acontecer qualquer problema, você não conta mais para a empresa!”. Há uma clara percepção de uso e de descartabilidade. Os objetivos perseguidos pela organização do trabalho capitalista instauram intrinsecamente as condições para o surgimento da humilhação social no trabalho. Os aspectos essenciais do método taylorista continuam a ser utilizados e aprimorados: a tentativa de aumentar o controle das 
atividades fabris por meio da imposição de ritmos ou metas (mesmo que contraditoriamente certas iniciativas sejam exigidas), a tentativa de compra da obediência (prêmios em dinheiro para os mais produtivos e formas de avaliação que premiam a submissão às exigências fabris), a tentativa de acirrar a competição e a desunião entre os trabalhadores (por meio das negociações individuais) e o impedimento de participação efetiva do trabalhador na gestão do trabalho.

A organização do trabalho fabril instaura, portanto, as condições para a experiência de humilhação social. Como afirma José Moura Gonçalves Filho, um dos fatores determinantes da experiência da humilhação social é a desigualdade política, entendida como "a exclusão recorrente de uma classe inteira de homens para fora do âmbito intersubjetivo da iniciativa e da palavra" (Gonçalves Filho, 1998). Essa compreensão pode ser adaptada ao espaço da produção: necessariamente as relações de trabalho instauram um espaço político onde os trabalhadores poderiam participar da definição dos objetivos e dos processos de trabalho. Nada parece mais incompatível com o modo de produção de mercadorias: gestos complementares ao funcionamento de máquinas, tempos impostos, objetos produzidos muitas vezes desconhecidos. A organização efetiva do trabalho fabril impõe uma exclusão, impedindo o trabalhador de participar do governo de seu próprio trabalho. Isso também não significa deixar de observar que os homens criam meios de resistir, impor limites de forma astuciosa à pressão por redução à condição de instrumento de produção. Antes, acreditamos que a análise científica do trabalho deve expor os fatores da organização social do trabalho que impedem que essa experiência de participação seja plena, integrando no processo produtivo a necessidade humana de enraizamento (Weil, 1996).

Isso nos leva a pensar em um problema específico ligado à reestruturação produtiva. A pesquisa de campo permitiu confirmar a ideia de que as empresas que oferecem melhores condições salariais, contratuais e de organização do trabalho, apaiam essas possibilidades sobre o esquema de "terceirização", contratando fábricas menores que, para manterem a competitividade, criam esquemas de sub-contratação e de precarização das condições de trabalho. À medida que a prática da terceirização e da realização de contratos temporários cresce, parece confirmar uma previsão feita por Durand:

De outro lado, pode-se mostrar que, durante a última crise de acumulação, o capital aprendeu uma nova conduta (nova ao menos em relação aos Trinta Gloriosos), qual seja, a sistematização da precariedade. Ou, dito de outra forma, a invenção da precariedade estrutural por meio da generalização do modelo núcleo/periferia, chegando até o cerne de suas engrenagens (gestão da força de trabalho, gestão do capital, concepção dos produtos, entre outras) (Durand, 2003).

Cabe aos psicólogos sociais do trabalho investigar e discutir quais seriam as características da organização do trabalho que poderiam sustentar verdadeiramente a participação dos trabalhadores na gestão do trabalho. O que significa para a psicologia social essa participação? Qual o contexto político, fora e dentro da fábrica, em que ela poderia efetivamente ocorrer? Que tipo de experiências psicossociais esperamos que sejam vividas para que esse termo descreva um efetivo avanço na organização do trabalho fabril? Observamos nesta pesquisa algumas dimensões do impedimento de participação: as máquinas dificultando o uso de habilidades manuais, exigindo um tipo de concentração maquinal (mesmo as máquinas CNC apoiam a separação entre programação e alimentação da máquina); a impossibilidade dos trabalhadores definirem os objetos e os tempos de trabalho e de relacionarem as próprias atividades com o atendimento de necessidades sociais concretas; a ameaça constante de falta de lugar caso a utilização do corpo não seja justificado por um cálculo econômico.

A possibilidade de governo do trabalho pelos próprios trabalhadores representa um importante critério pelo qual podemos observar se uma experiência de trabalho é aviltante ou satisfatória. Essa possibilidade envolve aspectos formais e informais da gestão efetiva do 
trabalho, os aspectos técnicos da organização e as formas de planejamento da produção social. Exatamente por isso a discussão realizada atualmente sobre o aumento da participação dos trabalhadores na gestão do trabalho possui relevância. Torna-se necessário contrapor tais discussões às experiências reais vividas pelos trabalhadores. Resta ainda uma pergunta fundamental que para ser respondida depende do estudo de teorias que possam relacionar as experiências de trabalho ao funcionamento da organização social da produção: o modo de produção capitalista poderia ser compatível com uma verdadeira superação de antigas formas de sofrimento no trabalho, como a monotonia e o tédio ligados às atividades simples, o adoecimento ligado ao uso mecânico do corpo (LER/DORT), o impedimento de participação efetiva na gestão do trabalho, o sentimento de dispensabilidade e a ameaça constante de exclusão pelo desemprego?

\section{Referências Bibliográficas}

Antunes, R. (2002). Os sentidos do trabalho. São Paulo: Boitempo.

Antunes, R. (Org.). (2006). Riqueza e miséria do trabalho no Brasil. São Paulo: Boitempo.

Bernardo, M. H. (2006). Discurso Flexível, trabalho duro: o contraste entre o discurso de gestão empresarial e a vivência dos trabalhadores. Tese de Doutorado, Instituto de Psicologia da Universidade de São Paulo, São Paulo.

Blanch Ribas, J. M. (2003). Teoria de las relaciones laborales: desafios. Barcelona : Universitat Oberta de Catalunya.

Braverman, H. (1981). Trabalho e capital monopolista. Rio de Janeiro: Zahar.

Burawoy, M. (1990). The politics of production. London, New York: Verso.

Dieese (1994). Trabalho e reestruturação produtiva: 10 anos de linha de produção. São Paulo: Dieese.

Durand, P. (2003). A refundação do trabalho no fluxo tensionado. Tempo Social, 15 (1), 140-157.

Ferro, J. R. (1990). Aprendendo com o "ohnoísmo" (produção flexível em massa): lições para o Brasil. Revista de Administração de Empresas, 30 (3), 57-68.

Geertz, C. (1989). A interpretação das culturas. Rio de Janeiro: LTC.

Gonçalves Flho, J. M. (1998). Humilhação social: um problema político em psicologia. Psicologia USP, 9 (2), 11-68.

Gonçalves Filho, J. M. (2003). Problemas de método em psicologia social: algumas notas sobre a humilhação política e o pesquisador participante. In A. M. B. Bock (Org.), Psicologia e compromisso social (pp. 193-240). São Paulo: Cortez.

Gorender, J. (1999). Marxismo sem utopia. São Paulo: Ática.

Lukács G (2003). História e consciência de classe. São Paulo: Martins Fontes.

Marx, K. (2004). Manuscritos econômico-filosóficos. São Paulo: Boitempo.

Ohno, T. (1997). O sistema toyota de produção: além da produção em larga escala. Porto Alegre: Bookman.

Sato, L. (2002). Prevenção de agravos à saúde do trabalhador: replanejando o trabalho através das negociações cotidianas. Cadernos de Saúde Pública, 18 (5), 1147-1166.

Sato, L. \& Oliveira, F. (2008). Compreender a gestão a partir do cotidiano de trabalho. Aletheia, 27 (1), 188-197.

Sato, L. \& Souza, M. P. R. (2001). Contribuindo para desvelar a complexidade do cotidiano através da pesquisa etnográfica em psicologia. Psicologia USP, 12 (2), 29-47.

Weil, S. (1996). A condição operária e outros estudos sobre a opressão. São Paulo: Paz e Terra.

Endereço para correspondência

bernardosvartman@hotmail.com
Recebido em: 28/11/2007

Revisado em: 13/10/2008

Aprovado em: 13/11/2008 